This item was submitted to Loughborough's Research Repository by the author.

Items in Figshare are protected by copyright, with all rights reserved, unless otherwise indicated.

\title{
Unpacking cohort social ties: the appropriateness of perceived social capital to graduate early career performance in construction project teams
}

PLEASE CITE THE PUBLISHED VERSION

http://dx.doi.org/10.1080/15578771.2016.1260667

\section{PUBLISHER}

(C) Associated Schools of Construction. Published by Taylor \& Francis

\section{VERSION}

AM (Accepted Manuscript)

\section{PUBLISHER STATEMENT}

This work is made available according to the conditions of the Creative Commons Attribution-NonCommercialNoDerivatives 4.0 International (CC BY-NC-ND 4.0) licence. Full details of this licence are available at: https://creativecommons.org/licenses/by-nc-nd/4.0/

\section{LICENCE}

CC BY-NC-ND 4.0

\section{REPOSITORY RECORD}

Thomson, Derek, Kate Carter, and Fiona Grant. 2019. "Unpacking Cohort Social Ties: The Appropriateness of Perceived Social Capital to Graduate Early Career Performance in Construction Project Teams". figshare. https://hdl.handle.net/2134/23946. 


\title{
Unpacking Cohort Social Ties: The Appropriateness of Perceived Social Capital to Graduate Early Career Performance in Construction Project Teams
}

\author{
Derek S. Thomson BSc (Hons), PgCAP, PhD, FHEA, MRICS \\ Loughborough University \\ Loughborough, United Kingdom
}

\author{
Kate Carter, BSc(Hons), BArch, MSC, \\ PhD \\ The University of Edinburgh \\ Edinburgh, United Kingdom
}

\author{
Prof. Fiona Grant, BSc (Hons), PhD, \\ FRICS, FCIOB, FHEA \\ Heriot-Watt University \\ Edinburgh, United Kingdom
}

\begin{abstract}
Construction project teams require social capital. When present in appropriate forms, it creates the social cohesion through which individuals accept project goals as their own. It lets team members share knowledge when present and reveal when it is missing. In education, social learning helps students appreciate the need for social capital appropriate to team performance. In practice, social capital enables the project team learning that overcomes project-specific challenges. Despite this importance, little is known about how students perceive social capital or the compatibility of that understanding with construction project needs.

To characterise this aspect of 'graduateness', collective understanding of social capital was elicited from construction students in a Scottish university by free recall. Analysis was structured around four dimensions of social capital: cohesion, legitimacy \& authenticity, sharing, and safety. Notions of friendship were found to dominate student understanding of the social capital even though this understanding derived from settings where the need for capital to support team performance is emphasised. The potential for misalignment between the capital that graduating students bring into practice with that required by project teams was apparent. The case for further investigation of this influence on early career development was established.
\end{abstract}

Key Words: social capital; social learning; team performance; social cohesion; social ties; interpersonal relationships

\section{Introduction}

\section{Considering Social Capital}

Social capital is prominent in both organisational and pedagogical theory. In the former, it is considered the "goodwill ... engendered by the fabric of social relations" (Adler and Kwon (2002: 17), with these relations bonding people together to promote individuals' career and organisations' commercial success. This enabling role causes the social capital present within an organisation to have commercial value, even though it cannot be commoditised or otherwise traded (Nahapiet and Ghoshal, 1998). In social learning, social capital is conceptualised as the "relationships of trust and information exchange that can facilitate subsequent social and economic opportunities" (Beattie and Thiele, 2016), highlighting the connection between the 
understanding of social capital that students develop in education and their post-graduation success.

Social capital has two dimensions: structural connections between individuals arising from informal communication patterns, and the relationships that emerge through the sustained interactions of these individuals. Considering teams in general, social capital is a precursor to learning because it facilitates knowledge exchange (Bartsch et al. 2013). It is a function of both network density and social cohesion (Wei et al., 2011), with the former being structural and the latter a consequence of social ties: that is, the nature of the relationships formed between individuals given that they may yield yet further dimensions of social capital such as trust, kinship, friendship and the like.

This study focuses on the relational origins of social capital to understand how students perceive their social ties and characterise the compatibility of that understanding with the demands of social learning in both education and in construction project teams. Although, as Oztok et al. (2015) note and implied by the above, there is no received definition of social capital, in this work it is considered the relational environment that emerges from the sustained interactions of individuals which, if appropriate, will support knowledge exchange to improve group goal fulfilment performance; be that group associated with social learning or a construction project.

\section{The Social Composition of Construction Projects}

Members of construction projects navigate unpredictable social forums that cannot be routinized (Grabber and Theil, 2015), demand flexibility (Anvuur et al., 2012), and require negotiation. To solve technical problems effectively, their construction projects must form socially cohesive communities. Acknowledging that experienced construction project managers rely on face-toface problem solving (Muir and Langford, 1994) and that social cohesion requires social capital of an appropriate form, project members must act purposefully to ensure project performance. Yet, Toor and Ofori (2008) discovered that graduating students are often ill-equipped to address this critical, social dimension of project performance.

To unpack student perceptions of social capital, a joint cohort of three construction management undergraduate programmes was studied. A survey was performed three-quarters of the way through its degree programme: a sufficient period for social capital traits to become salient.

\section{Construction Projects and Social Capital}

Whether or not a construction project can be considered a team largely depends on the presence of social capital appropriate to unified action. Social capital turns construction projects from loose associations of individuals to interwoven teams with mutual objectives (Anvuur et al., 2012). When appropriate to project performance, social capital - that is, the goodwill between project team members (Alder and Kwon, 2002) - creates "a sense of togetherness and belonging" (Hoegl and Gemuenden, 2001: 438). This social cohesion makes project members feel connected. It encourages them to adopt project goals as their own and to help others also do so (Ballesteros-Pérez et al., 2012). They become integrated team members through an identification process that requires "role socialisation" (Anvuur et al., 2012: 721) in which 
"actions are shaped, redirected, [and] constrained by the social context" (Coleman, 1988: S96). This socialisation requires team members to purposefully nurture appropriate forms of social capital in their relationships (Lin, 2015), yet many find this difficult. Gorse and Emmitt (2007) found, for example, that team members tend to discuss technical issues without overtly addressing essential trust, cohesion and teamwork.

Social capital facilitates social learning among construction project members, allowing them to build intellectual capital by developing new methods and new technical solutions (Keung and Shen, 2013). Social capital must be present within relationships as a prerequisite to the generation and effective use of intellectual capital (that is, shared knowledge). Social ties are therefore themselves a valuable project resource (Nahapiet and Ghoshal, 1998). The appropriateness of social capital to project performance is determined by team members' joint perception of their relationships (Koh and Rowlinson, 2014). If project members perceive their relationships in ways inappropriate to project performance goals become divergent, mutual benefit is not perceived, and some members are viewed as benefitting more than others. Nahapiet and Ghoshal (1998) identified three dimensions to social capital: structural, cognitive and relational. Structural perspectives (see, for example, Pryke (2012)) cannot characterise how social capital is perceived because they only identify the presence of social ties and not their nature. The cognitive and relational dimensions are examined by this study from the perspective of graduating students about to enter the project-based construction industry in which learning is required to overcome project challenges. Because most students pass through higher education during their formative years, the understanding of social capital and its role helping teams perform will frame how these students develop through education and their subsequent professional career. If inappropriate to professional settings, their understanding and expectations of how social capital should be developed and deployed will constrain professional development both immediately post-graduation and thereafter because formative understanding can only be partially offset by later experiences through professional life.

\section{Students and Social Capital}

Maghiar et al. (2015) suggested that graduating students' ability to build social capital should transfer directly from education into industry contexts: but students may misunderstand forms of capital appropriate to those new contexts. Graduating students enter practice with understanding inherited from formal social learning and wider social settings. In higher education, cohort membership provides a persistent familial context in which shared values, norms and attitudes emerge (Havnes, 2008), building capital that may cumulate in friendships. When transferred into industry, this social capital may - or may not - help graduating students build social cohesion and intellectual capital within construction projects.

This uncertainty about graduating student understanding of social capital raised three research questions:

RQ1: Is the form of social capital that social learning claims to build compatible with that required for construction project team performance?

RQ2: How do students perceive social capital within their social learning experiences?

RQ3: Are student perceptions of social capital compatible with the forms required by social learning and for construction project team performance? 


\title{
The Social Capital Required by Construction Projects
}

\author{
Social Capital and Cohesion
}

As Temporary Multi-Organisations (TMOs) (Pauget and Wald, 2013), construction projects involve many distinct, specialist organisations (Keung and Shen, 2013) brought together in formal ways. Relationships are contractual between organisations but interpersonal at the individual level, relying on social networks to function as coherent teams (Mutis and Issa, 2011). Accordingly, two systems of institution are at play: the legally incorporated entities contracting with each other through formal, codified mechanisms; and the multiplicity of individuals interacting with each other through patterns that form socially constructed relationships independent of contractual ones. It is within these neo-institutions that, if the project is truly collaborative and, therefore, cohesive, social cohesion develops and formal organisational boundaries become diffuse.

Social capital is differentiated from social cohesion within teams; be they in education or practice. Cohesion can only exist in the presence of capital that causes team members to seek mutual goals and to consider their individual success contingent upon the group's collect success in achieving common goals. Once this interdependency is established, appropriate forms of capital then allow the exchange and integration of knowledge; a process intimately associated with learning (again, be it in education or practice). In construction projects, knowledge exchange impacts positively on project performance (Vincenzo and Mascia 2012) and improves health and safety (Koh and Rowlinson, 2014).

Projects become socially cohesive teams when members wish to remain in them (Hoegl and Gemuenden, 2001). Social cohesion, with its "interpersonal attachments" between individuals (Andrews et al., 2008: 742), is positively correlated with team effectiveness (Di Vincenzo and Mascia, 2012). It facilitates the reciprocal social transactions that build trust (ibid.) and enables knowledge sharing (Coleman, 1988), even when that knowledge is unequally distributed among team members. Trust reaffirms team cohesiveness and allows team members to openly and reciprocally (Andrews et al., 2008) share information (Coleman, 1988) for mutual benefit. Cohesive teams can readily share (Wei et al., 2011) and reuse (Bartsch et al., 2013) knowledge in new ways to generate the intellectual capital required to solve project-specific and, thus, novel problems. Individuals can act authentically because, in the presence of peers perceived as friends, they can function openly and truly, without filtering or otherwise skewing their contributions.

\section{Social Capital and Project Learning}

As temporary multi-organisations, construction projects need "vast amounts of social capital" (Vorakulpipat et al., 2010: 145) to overcome their structural fragmentation and develop shared understandings through face-to-face exchanges. Building this social capital can be catalysed by introducing appropriate pre-existing capital from pre-existing personal relationships (Braun et 
al., 2012). Team members can contribute "career capital" (Grabher and Theil, 2015: 3), motivating them to ensure project success to maintain their personal reputation. This personal stake causes project members to only introduce appropriate relationships, establishing an "external quality filter" (ibid.: 5) and promoting the legitimacy of further project members introduced in this way. These legitimate ties span projects and create bridges for diffusing intellectual and social capital between them (Bartsch et al., 2013), helping the industry to improve its collective performance (albeit potentially creating intellectual property issues).

The improved understanding that results from project learning when legitimate team members collaborate authentically is often tacit and cannot be conveyed through contractual documentation (Di Vincenzo and Mascia, 2012). Authentic project learning requires project members to honestly reveal absent as well as present understanding (Sense, 2011). This requires the social safety provided by trust (Pauget and Wald, 2013). Cohesion and legitimacy create this safe learning space (that is, an internal project environment conducive to the development of intellectual capital). Authentic individuals act freely within it. Cohesion provides the reciprocal trust that allows absent knowledge to be revealed while legitimacy eases the free exchange of knowledge. In summary, social cohesion creates the safe social space (psychologically safe and quite distinct from safety in the sense of 'health and safety') in which knowledge can be freely exchanged, as and when required, to solve project-specific challenges. Moreover, cohesion provides the interdependency that causes individuals to adopt project goals as their own; promoting knowledge exchange even when it is unequally distributed within the project team. In the presence of cohesion, success becomes a mutual goal rather than something to be achieved by one individual at the expense of others.

\section{Social Capital and Construction Project Performance}

Dysfunctional construction project teams have inappropriate social capital that cannot support the above learning mechanisms. To avoid this, and as Hoegl and Gemuenden (2001) note, social capital must be purposively nurtured to ensure its appropriateness. Social capital appropriate to construction project team performance enables the free exchange of information and the revealing of the presence (or otherwise) of understanding between team members that, in turn, enables the group learning required to solve novel technical challenges. This 'appropriate' form of social capital can be considered to have four dimensions, viz.:

1. Cohesion, which, as discussed at length above, associates social capital with the open exchange of information within a team and the desire of individuals to remain members of that team.

2. Legitimacy \& authenticity, which associates social capital with a valid reason for every project member to be in the team. This reason is grounded in the intellectual capital they help build (legitimacy) and their honesty in doing so (authenticity). Legitimacy is also associated with individuals enacting their formal role (Ahn et al., 2014) to help the project make decisions (Handford and Matous, 2015) and meet its goals (Di Vincenzo and Mascia, 2012, Coleman, 1988). 
3. Sharing, which associates social capital with the free exchange of knowledge for mutual benefit. This requires social capital to generate "higher communication efficiency" (Lin, 2015: 4014097), connecting organisational members with differing expertise (Di Vincenzo and Mascia, 2012).

4. Safety, which associates social capital with a mutual vulnerability that allows individuals to reveal absent understanding. This social capital stimulates the generation of intellectual capital as it allows speculative suggestions to be made. It requires social ties associated with common values and emotions (Gorse and Emmitt, 2007), bonding (Adler and Kwon, 2002), reduced personal barriers, improved confidence and friendship (Vorakulpipat et al., 2010).

\section{The Social Capital Required for Social Learning}

Having establish the role of social capital in construction project teams, its role in social learning must now be examined.

\section{Social Learning}

Social learning is more effective than individualistic or competitive approaches (Gundenson and Moore, 2008) because it exploits the "problem-solving potential of a group, a network, an institution or a community" (Wildemeersch, 1998: 252). Repeated social exchanges endow students with shared social, emotional and educational traits and attitudes (Gundeson and Moore, 2008) that may promote or impede learning (Haythornthwaite, 2002). In this context, social capital creates social cohesion, students experience "co-operative learning" (Summers and Svinicki, 2007: 56) and perceive themselves to share developmental goals, leading to mutual support and the co-development of understanding (Orsmond et al., 2011). They will also want the learning group to continue to exist (Festinger, 1950: 274).

\section{Cohesion and Trust}

Learning becomes cooperative when situated in a "cohesive community with relationships of mutuality and shared understandings" (Lindkvist, 2005: 1189). In such a community, the negotiation of "particular rules of discursive practice" (Mann, 2001: 10) builds cohesion. Cohesion, in turn, leads to willingness to learn and alignment with collective goals. Cohesion is established by sustained interactions conducive to learning (Johnson and Johnson, 2009) and depends on appropriate student relationships (Lave, 1996). Ideally, these relationships will involve reciprocal benefit and will, therefore, build trust and bring socio-emotional benefit to cohort members (Gundeson and Moore, 2008). Trust allows students to reveal their absent understanding (Blumenfeld et al., 1996; Lizzio and Wilson, 2010) and highlight differences in understanding (Yeatts and Hyten, 1998). It also eases information sharing (Deeter-Schmelz et al., 2002) and establishes the mutual accountability that underpins motivation (Orsmond et al., 2011) by making students feel responsible for peers' learning performance as well their own (Johnson and Johnson, 2009). This need for collective, rather than individual, performance signifies cohesion. 


\section{Appropriate Social Capital}

Social relationships will only support collective social learning if they "contribute to academic motivation, engagement, and achievement" (Martin and Dowson, 2009: 351), are associated with mutual goal fulfilment (Summers and Svinicki, 2007) and provide an "interpersonal congruence" from which shared understanding is built (Decuyper et al., 2010: 117). If students "perceive that they can reach their goals if and only if others in the group also reach their goals" (Summers and Svinicki, 2007: 56) then interdependency results. This form of cohesion is characterised by cohorts with widespread communication that is "positively-orientated" (Deeter-Schmelz et al., 2002: 116) towards learning because it helps students learn collaboratively (Johnson and Johnson, 2009) but this communication will only develop if the underlying social capital is appropriate. When the capital is appropriate, it can overcome any latent perceptions of unfairness by enabling knowledge sharing even when that knowledge is not uniformly distributed among learning group members (Motos 2016; Lozares et al. 2011).

Building appropriate social capital (namely, that which results in cohesion) requires purposeful action (Breen and Lindsay, 2002). Students must "make a conscious, continued effort to coordinate their language and activity with respect to shared knowledge" (Roschelle and Teasley, 1995: 94, cited by Van den Bossche et al., 2006). Indeed, they should consider this effort an investment that increases their ability to realise an envisioned future (Andrew 2014). Some students find purposeful action unconscionable; considering it an anathema to trust and friendship (Villar and Albertín, 2010). Yet, if appropriate social capital is not nurtured, students risk merely absorbing group understanding rather than contributing to it (Orsmond et al., 2011). Such "social loafing" (Blumenfeld et al., 1996: 38) signifies a lack of group cohesion and inappropriate learning protocols (Wildemeersch et al., 1998): in other words, inappropriate social capital.

\section{Extracting Social Capital from Personal Networks}

Formal, tutor-instigated learning episodes are only a small component of a student's social learning context (Dawson, 2008: 226; Cho et al., 2007; Wildemeersch et al., 1998). Students also rely on their personal networks. Even though a student's personal network coincides with the cohort body, it comprises non-educational ties that the student cares about (Draper, 2008). Examples include ties from common living arrangements (Wilcox et al., 2005) and pre-existing friendships (Cho et al., 2007). Although social-cultural context (Handley et al., 2006) and "activities and identities" outside formal education (Baker and Lattuca, 2010: 814, Orsmond et al., 2011) frame learning performance, they may offer forms of social capital inappropriate to effective group learning.

Personal networks are different to students' learning networks. The latter provide a learningfocused cohesion (Johnson and Johnson, 2009) and create a "shared expectation ... that ... educational needs will be met through common commitment to shared goals" (Summers and Svinick, 2007: 58). Shared expectations, interdependency and cohesion must be present for students to help each other learn (Eggens et al., 2007). Yet, students may find it difficult to identify the presence of these traits in the social capital available (Handley et al., 2006). 
In addition to proximity (Van den Bossche et al., 2006, Deeter-Schmelz et al., 2002), learning requires "emotional, informational, or instrumental resources" (Eggens et al., 2007: 557). Yet students can confuse the "quality of the emotional bonds of friendship such as liking, caring and closeness among group members" (Van den Bossche et al., 2006: 499) with that required for learning. Along with Lizzio and Wilson (2010), they suggested that an over-reliance on friendships to support learning may allow harmful groupthink to emerge. Students may forego the debate required to build collective understanding (Strauus and Young, 2011; Decuyper et al., 2010; Johnson and Johnson, 2009: 368) and suggestions may be accepted without collaborative critique (Van den Bossche et al., 2006). Decuyper et al. (2010: 123) implied that the capital associated with learning networks and personal networks must be differentiated, suggesting that social learning will only be effective if capital from personal networks is avoided altogether.

Wilcox et al. (2005) took a more pragmatic view, suggesting that students must filter that capital so that only individuals on whom they interdepend are introduced to the learning group. Doing so will develop its social cohesion.

\section{Comparing Social Capital in Learning and Construction Project Practice}

To resolve RQ1, the theoretical role of the social capital considered by literature as required for construction project team performance was compared with that theoretically available from social learning. This comparison provided an interpretative framework (Table 1) to characterise graduating student preparedness for their initial construction industry roles, formed around the four dimensions of social capital: Cohesion, Legitimacy \& authenticity, Sharing, and Safety identified above.

As seen in Table 1, the dimensions of Legitimacy \& authenticity and Sharing were not prominent in established theoretical models of social learning. Graduating students may, therefore, fail to appreciate their need to purposefully develop these dimensions of social capital within construction project teams. Further insight into this was provided in the address of RQ2, in which student perceptions of social capital were elicited. 


\section{TABLE 1: Comparison of Social Capital in Construction Projects and Social Learning}

\begin{tabular}{|c|c|c|}
\hline Dimension & $\begin{array}{l}\text { Role in Construction Project } \\
\text { Teams }\end{array}$ & Role in Social Learning \\
\hline Cohesion & $\begin{array}{l}\text { Enables the free and open } \\
\text { exchange of information and } \\
\text { continued group existence. } \\
\text { Builds shared ownership of } \\
\text { project goals. }\end{array}$ & $\begin{array}{l}\text { Provides motivation and group } \\
\text { persistence. Leads to interdependency } \\
\text { and perceived need for collective } \\
\text { learning success. May lead to } \\
\text { inappropriate social capital if built from } \\
\text { personal ties rather than ties focused on } \\
\text { learning alone. }\end{array}$ \\
\hline $\begin{array}{l}\text { Legitimacy \& } \\
\text { authenticity }\end{array}$ & $\begin{array}{l}\text { Ensures that all project actors } \\
\text { are considered valid team } \\
\text { members and that they } \\
\text { contribute honestly in } \\
\text { accordance with their formal } \\
\text { roles and their personal self- } \\
\text { image. }\end{array}$ & $\begin{array}{l}\text { Legitimacy not considered, in the main, } \\
\text { as students unable to influence cohort } \\
\text { membership although they may rely on } \\
\text { personal ties formed within that cohort. } \\
\text { Authenticity not considered as students } \\
\text { are not framed by professional role } \\
\text { stereotypes. When attempting to rely on } \\
\text { friendships for learning, students may } \\
\text { struggle to determine when the available } \\
\text { social capital is appropriate to that } \\
\text { learning. }\end{array}$ \\
\hline Sharing & $\begin{array}{l}\text { Ensures that social ties connect } \\
\text { disparate bodies of knowledge } \\
\text { and do so for mutual benefit. }\end{array}$ & $\begin{array}{l}\text { Not recognised as social learning theory } \\
\text { promotes the cooperative development of } \\
\text { understanding rather than the sharing of } \\
\text { pre-existing knowledge. }\end{array}$ \\
\hline Safety & $\begin{array}{l}\text { Allows absent knowledge to be } \\
\text { revealed. Career capital from } \\
\text { pre-existing professional } \\
\text { friendships may create the } \\
\text { required social safety. Other } \\
\text { forms of bonding and shared } \\
\text { values also required. }\end{array}$ & $\begin{array}{l}\text { Pre-existing friendships from personal } \\
\text { networks can help form socially safe } \\
\text { spaces, but this pre-existing social capital } \\
\text { may not be conducive to learning. } \\
\text { Students can find it difficult to determine } \\
\text { if this is the case. }\end{array}$ \\
\hline
\end{tabular}




\section{Research Design and Method}

\section{Surveying Student Perceptions of Social Capital}

To address RQ2, perceptions of social capital were elicited from students attending a Scottish university. A typical undergraduate cohort spanning three construction professions (quantity surveying, project management and construction management) was studied in the third year of a four-year joint degree programme. As this degree programme did not include a sandwich year, all student understanding of social capital was developed from their educational experiences. Any short-term summer placements secured by individual students were not considered influential given that social capital requires a sustained period of interaction to develop, and that only the persistent cohort could provide the required setting.

Twenty (26\%) self-selecting cohort members participated in the study, providing a random sample. Although small, this sample was entirely appropriate to the free recall elicitation method. Barnard and Ryan (2010) have found that a well-formed cultural domain's constituent concepts will be elicited from as few as fifteen to twenty informants (2010:167), with Schrauf and Sanchez further noting that "sample sizes of twenty to thirty informants ... are considered sufficient to provide ... a reasonable survey" (2010: 71). Studies of less well defined boundary conditions use sample sizes more typically in the low to mid-thirties. For example, Quinlan (2004) used thirty informants (representing one-fourth of the population; as here) to elicit understanding of bush medicines from a Dominican village community. Other studies have generated valid results from as few informants as thirteen (Brewer, 1995a) while, at the other extreme, Quinlan (2005) required over 1,800 free lists from an open survey and Thompson and Zhang (2006) aggregated six surveys of c. 180 students each from international universities to characterise previously undefined domains. In the middle of this range, poorly-defined domains have been characterised using sample sizes in the hundreds (Hough and Ferraris, 2010: $n=184$; Ares and Delize, 2010: $n=200$; Winkler-Rhoades, et al., 2010: $n=667$ ). In short, and as Ryan et al. (2000) note, free recall is robust with both large and small samples. The sample used in this work is valid. After three years of sustained interaction, the cultural domain comprising the social ties between cohort members can be considered well-formed and non-contentious, justifying this study's position at the smaller end of above extremes.

\section{Data Analysis}

As social ties are normatively formed, their collective perception forms a cultural domain. This domain was elicited using standard freelisting protocols (e.g. Borgatti and Halgin, 2011; Bernard and Ryan, 2010). Perceptions were captured via an in-class activity to ensure elicitation frame parity between students. To avoid social cueing (Brewer, 2002), social capital was not discussed with participants. Instead, they were simply asked their views of 'knowing' a cohort peer. The frame followed Bousfield and Barclay's (1950) well-established schema, viz.: "When you think about what it means to know one of your colleagues in your class, write down a single word for each additional, related thought that comes into your mind." After ten minutes of individual free recall, 421 concepts were elicited. This sample was analysed using Thomson et al.'s (2012) abridged protocol. Lemmatisation reduced the data to 140 concepts. Adopting Brewer's 
clarification (1995a; 1995b), concepts expressed once were discarded as external to the domain, leaving 47 concepts for salience analysis. Salience indices were calculated per Sutrop (2001).

\section{Results}

Concepts were ordered by salience index, normalised to a notional index of 1 , representing a hypothetical concept elicited first from every participant per Sutrop (2001). Salient concepts meriting further investigation were identified by scree plot (Figure 1) following Borgatti and Halgin (2011), Bernard and Ryan (2010) and Thompson and Juan (2006) among others. Fifteen salient concepts were identified for further exploration (Table 2).

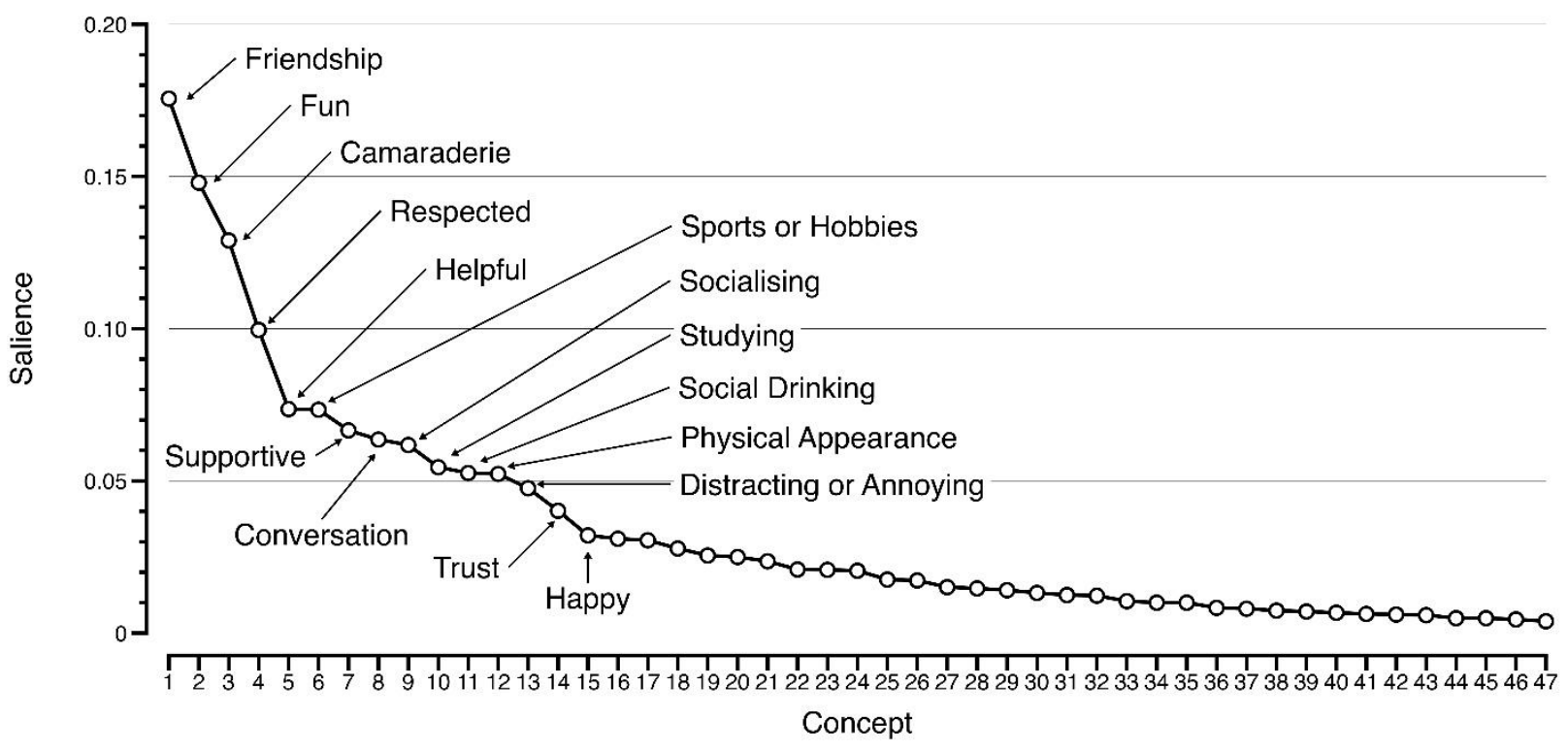

FIGURE 1: Scree plot of collectively recalled cognitive concepts

As illustrated by Figure 1, the concepts most salient within the cultural domain (Friendship, Fun, Camaraderie and Respected) implied the presence of social cohesion. Observing the potential for conflict between the social capital that students may associate with personal networks with the forms required for construction project team and social learning performance concluded RQ2. Whether or not the observed cohesion (including the less salient concepts above the scree plot knee in Figure 1) is conducive to either construction project team performance or social learning required abductive inferences to be drawn in the exploration of RQ3.

\section{Interpreting Student Perceptions of Social Capital}

RQ3 considered the students' collective perception of social capital considering the fourdimensional model of that required for construction project team performance (i.e. mutual goal fulfilment) as illustrated by Table 2 . 
TABLE 2: Salient concepts mapped against dimensions of social capital required for construction project team performance

\begin{tabular}{ccccccc}
\hline \multicolumn{2}{c}{ Social Capital Concept } & \multicolumn{5}{c}{ Social Dimension of Construction Project Team } \\
Performance
\end{tabular}

Note 1: Aspects of social capital not associated with construction project team performance.

Note 2: Concept associated with Legitimacy alone.

Note 3: Concept associated with Legitimacy \& authenticity.

\section{Concepts Related to Safety}

In the context of this study, it is important to differentiate safety in the sense of actions taken to minimise the risk of physical harm, usually on site, and social Safety, namely the creation of an open, cohesive forum in which the presence of understanding and - critically - its absence can 
be revealed to others without critique or harmful consequence. This study considers Safety in the latter sense only.

Safety (i.e. social safety) was the most salient dimension in the collective perception, with a salience index of 0.467 across five constituent concepts. These constituents were inferred to be personal in nature as they would likely be drawn from personal ties rather than ties purposefully nurtured to support learning. This inference is evidenced by the presence of Friendship (ranked 1st overall, salience index $=0.176$ ), Camaraderie ( $3 \mathrm{rd}, 0.129)$ and Supportive ( 7 th, 0.067) as the most salient concepts associated with this dimension. The association of these concepts with friendship and socialising rather than learning specifically suggests that students may not fully appreciate the need for common values and norms (Villar and Albertín, 2010) oriented towards learning. This inference is counteracted to some extent, however, by the presence of learningoriented Studying (10th, 0.055) and Trust (14th, 0.040), albeit with considerably less salience.

\section{Concepts Related to Cohesion}

Cohesion was the second-most salient dimension in students' collective perception (salience index $=0.460$ ), although the distinction of this concept's salience from that of Safety is notional (Figure 2).

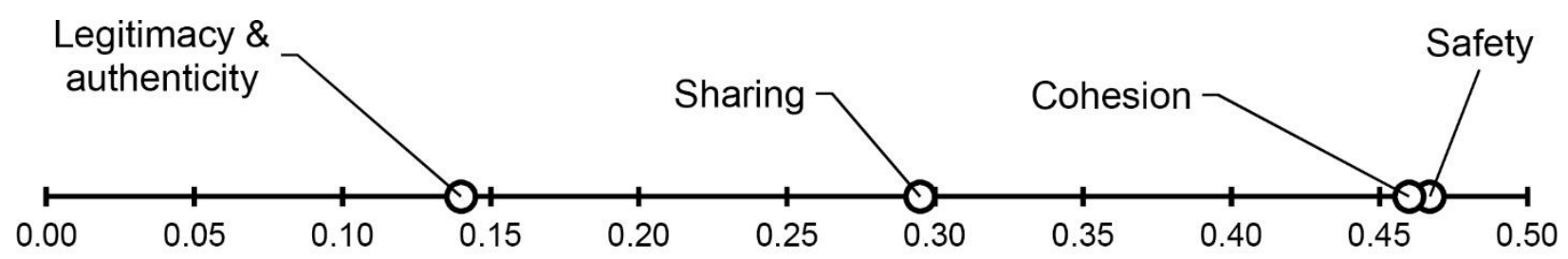

Summed Salience Index

\section{FIGURE 2: Observed saliences of dimensions of social capital required for construction project team performance}

This is partly due to the reoccurrence of Friendship (ranked 1st overall, salience index $=0.176$ ) and Camaraderie (3rd, 0.129). Their presence represents the building of common values noted by Handley et al. (2006) and the interdependence noted by Hoegl and Gemuenden (2001) required for a cohesive and sustainable construction project team. The remaining concept of Socialising (9th, 0.062) implied that Cohesion might not be entirely conducive to fulfilling mutual project goals. Similarly, although Social drinking (11th, 0.053), in Western contexts at least, can build cohesion and common values, it may also result in behaviours or norms counter to collective team performance. However, although not yet recognised in organisational theory, recent evidence from educational settings suggests that cohesion can result from behaviours that would, superficially at least, be considered counter-productive to effective learning and group performance such as gossiping and teasing (Hendry et al. 2016). Indeed, this ambiguity is emphasised by Chipperfield (2012) in respect of Camaraderie, who suggested that it might result from personal ties introduced to the project rather than any purposeful effort to build social capital. In contrast, the presence of Trust, although of low salience (14th, 0.040), evidenced Cohesion due to Pauget and Wald's (2013) association of trust with Safety. 


\section{Concepts Related to Sharing}

As Figure 2 illustrates, a marked gap in summed salience was observed between Cohesion and Sharing (salience index $=0.295$ ) as the next-most prominent dimension. Friendship again ranked first overall (index $=0.176$ ) within this dimension, providing further evidence that students may struggle to differentiate personal relationships from those conducive to team performance and social learning. The remaining concepts related to Sharing were Conversation (8th, 0.064) and Studying (10th, 0.055). Conversation is clearly a precursor to open knowledge exchange for mutual benefit (Coleman, 1988; Andrews et al., 2008). The relative prominence of this concept in the dimensions implied that, along with revealing missing knowledge (Sense, 2011), this understanding of social capital would likely help graduating students contribute to intellectual capital within construction project teams.

\section{Concepts Related to Legitimacy \& authenticity}

The final dimension - Legitimacy \& authenticity - had limited representation in student perceptions of social capital. Its low salience (0.140), with only two constituent concepts observed, suggested that students do not recognise this aspect of construction project team performance. Critically, although the literature associated Legitimacy with a filtering process by which only personal ties conducive to group learning would be introduced, it was not observed as an independent concept. Instead, its presence was inferred from the presence of Respected (ranked 4th overall, salience index $=0.100)$ and, to a much lesser extent, Trust (14th, 0.040). The second aspect of this dimension - Authenticity - was also inferred from the presence of Trust as trust implied action in accordance with an assigned social role. Further reflections on this underrepresented dimension of construction project team performance are presented below.

\section{Discussion}

In response to RQ3, the social capital present within the studied cohort was found to emphasise personal ties, with cohort peers perceiving each other as friends rather than social learning accomplices. The suggestion that students purposefully build learning-oriented social capital was not supported. It is not clear if this lack of action is caused by Villar and Albertín (2010)'s suggestion that students find the practice objectionable, or if the need for the practice is simply not recognised. The salience of friendship and its dominance over several dimensions of the social capital required for construction project team performance may cause students to seek it in inappropriate forms in their early career.

In principle, the salience of Safety within their understanding of social capital should allow newly-graduated students to reveal missing understanding or knowledge and, thus, act professionally by not acting beyond their current expertise. Yet, the concepts associated with Safety overlapped those associated with - again - friendship. It is suggested that graduating students may over-emphasise personal ties and goals over construction project team goals. 
As foreseen by the alignment of theoretical perspectives of social capital in construction project teams and social learning (recall Table 1), the two remaining dimensions of social capital appropriate to construction project team performance - Sharing and Legitimacy \& authenticity were markedly less salient in student understanding. Legitimacy \& authenticity was present with such limited salience (recall Figure 2) that it could be considered absent. This is at odds with Grabher and Theil's (2015) observation that professionals will filter the personal ties they introduce to ensure legitimacy, suggesting that the need for this filter is not yet appreciated by students. Given the dominance of friendship over their perceptions of social capital, graduating students may attempt to rely on inappropriate personal ties to support their early career development. No evidence of authenticity was observed but this may be expected as, at the time of survey, cohort members would not yet have had the opportunity to gain experience and understanding of their personal approach to their formal, professional role in practice.

\section{Limitations}

The scope and complexity of this exploratory study has been sufficient to suggest that student perceptions of social capital acquired during their formal, albeit social, learning may impact their early career development. The intent was not to provide a definitive conclusion but, rather, to determine if this perception may be problematic. In finding this to be the case, this study has established the case for further, confirmatory work with a wider sample. Such further work could widen the survey so that generalisable findings could be produced; as this work sought merely to determine if there was an issue in students' collective cognition that merited further study.

A limitation is caused by the higher education institution in which the study is performed. This was a Scottish plate-glass university, shaped by the vocational nature of the degree programme, a widening access agenda, and a diverse socio-economic profile. Extending the study to further types of higher education institution would clarify the influence of institution type, cohort composition and so forth. The small, but typical, sample creates a related limitation. As social protocols exist within a cultural setting, it is likely that the findings of this work will only be applicable to nations sharing similar, Western, attitudes towards social learning. The applicability of this work to other cultural contexts will require clarification by performing similar studies in other settings.

Finally, the nature of the student's industry role immediately after graduation requires consideration. It could be argued that any understanding of social capital transferred from education into industry could be readily supplanted by the new graduate as they acquire practical experience. This would be particularly important if the understanding developed in education was inappropriate and, due to incompatibility with the understanding collectively held by existing project team members, limited the graduate's ability to fit into the project's social institutions. The authors reject this suggestion by contending that, as most students experience higher education during their formative years, these initial understandings - including those connecting social capital to team learning performance - will exert considerable influence through subsequent years, acting as a fundamental interpretative frame. This speculation cannot, of course, be proven within an isolated study such as this, but it poses interesting questions for further examination. If educators argue that the value of a degree is realised over students' future 
careers, then that influence must also be conceptualised in terms of, and framed by, the student's understanding of the intangible aspects of their performance; among which social capital is pivotal.

\section{Conclusions and Further Work}

Perhaps unsurprisingly, this exploratory study has shown that a typical student cohort perceives its social ties largely around perceptions of friendship rather than learning. Little evidence of social capital forms unique to learning was found, suggesting that students may not be aware of the importance of such capital in the act of learning; be it in education or construction project settings. In reaching this conclusion, this work has reaffirmed Toor and Ofori's (2008) discovery that graduating students can be ill-equipped for their early career performance in construction teams. It has extended this insight in the specific context of construction management undergraduates by establishing: the dominance of friendship in their cognition of social capital; the absence of the social safety required for learning group and project team performance; and the relative absence of the further social capital elements required for construction team performance, namely Sharing and Legitimacy \& authenticity.

Of the four dimensions of social capital required for construction project team performance, only Safety and Cohesion can be considered clearly salient and, interestingly, salient to roughly the same extent. This may be considered an association, or overlapping, of the two dimensions in students' collective cognition. This ambiguity is, in turn, present in the literature. Although Baker and Lattuca (2010), Summers and Svinicki (2007) and Osterman (2000) all associate a sense of belonging and community with a socially cohesive cohort, they do not clearly establish the role of that cohesion in promoting learning performance beyond providing a context for the development of a social safety. Differentiating Safety from Cohesion, and doing so in both social learning and construction project team contexts, is therefore a potentially fruitful ground for further investigation.

The remaining two dimensions of appropriate social capital - Sharing and Legitimacy \& authenticity - were markedly less salient suggesting that students are ill-prepared for the social aspects of their early career development. This reveals two fronts for further study: the need (and ethical obligation) of educators to raise these dimensions of social capital in students' minds by creating social learning situations in which they can be appreciated and nurtured; and the impact of this absence of understanding on graduating students' early career performance.

In terms of the research questions, theoretical understanding of the role of social capital in social learning were found to be somewhat compatible with those in theoretical understanding of construction projects teams, with the dimensions of Cohesion and Sharing present in both, but those of Legitimacy \& authenticity and Safety only present in the latter (RQ1). Notions of friendship were found to dominate student perceptions of social capital (RQ2). In response to RQ3, student perceptions of social capital harboured the risk that students would attempt to overrely on personal ties and use them to nurture inappropriate forms of social capital within construction project teams. This paper concludes with further questions around the nature of this risk and, indeed, if it is a risk of impeded performance at all. Although the concepts that students 
associate with social capital in education are, overall, misaligned with social capital appropriate to construction project performance, some of the salient concepts raise further questions. Fun (salience index $=0.148$ ), for example, is of intermediate salience to Friendship (0.176) and Camaraderie $(0,129)$, both of which are aligned with the dimensions of Safety and Cohesion implying that Fun may, in fact, contribute to social capital around these two dimensions in a way not currently explained by literature. As this study has established this presence of Fun along with Helpful and Sports or hobbies as concepts that may have a similar, as yet not understood role, further work must determine their consequences.

\section{References}

Adler, P.S., \& Kwon, S.W. (2002). Social capital: prospects for a new concept. Academy of Management Review, 27(1), pp. 17-40.

Ahn, S., Lee, S., \& Steel, R.P. (2014). Construction Workers' Perceptions and Attitudes toward Social Norms as Predictors of Their Absence Behavior. Journal of Construction Engineering and Management, 140(5), p.04013069.

Andrews, M.C., Kacmar, K.M., Blakely, G.L., \& Bucklew, N.S. (2008). Group Cohesion as an Enhancement to the Justice - Affective Commitment Relationship. Group \& Organization Management, 33(6), pp. 736-755.

Andrew, M. (2014). Community and Individuality: Teaching and Learning Insights From a Postgraduate Online Writing Program. SAGE Open, 4(3), pp. 1-13

Anvuur, A.M., Kumaraswamy, M., \& Fellows, R. (2012). Perceptions of status and TMO workgroup cooperation: implications for project governance. Construction Management and Economics, 30(9), pp. 719-737.

Baker, V.L., \& Lattuca, L.R. (2010). Developmental networks and learning: toward an interdisciplinary perspective on identity development during doctoral study. Studies in Higher Education, 35(7), pp. 807-827.

Ballesteros-Pérez, P., González-Cruz, M.C., \& Fernández-Diego, M. (2012). Human resource allocation management in multiple projects using sociometric techniques. International Journal of Project Management, 30(8), pp. 901-913.

Bartsch, V., Ebers, M., \& Maurer, I. (2013). Learning in project-based organizations: The role of project teams' social capital for overcoming barriers to learning. International Journal of Project Management, 31(2), pp. 239-251.

Bernard, H.R., \& Ryan, G.W. (2010). Analyzing Qualitative Data: Systematic Approaches, Thousand Oaks, CA: SAGE Publications.

Beattie, I.R. \& Thiele, M. (2016). Connecting in Class?: College Class Size and Inequality in Academic Social Capital. The Journal of Higher Education, 87(3), pp. 332-362.

Blumenfeld, P.C., Marx, R.W., Soloway, E., \& Krajcik, J. (1996). Learning With Peers: From Small Group Cooperation to Collaborative Communities. Educational Researcher, 25, pp. 37-40.

Borgatti, S.P., \& Halgin, D.S. (2011). Elicitation Techniques for Cultural Domain Analysis. In J. Schensul \& M. LeCompte, eds. The Ethnographer's Toolkit, Volume 3. Walnut Creek: Altamira Press. 
Bousfield, W., \& Barclay, W. (1950). The Relationship between Order and Frequency of Occurrence of Restricted Associative Responses. Journal of Experimental Psychology, 40(5), pp. 643-647.

Braun, T., Müller-Seitz, G., \& Sydow, J. (2012). Project citizenship behavior? — An explorative analysis at the project-network-nexus. Scandinavian Journal of Management, 28(4), pp. 271-284.

Breen, R., \& Lindsay, R. (2002). Different disciplines require different motivations for student success. Research in Higher Education, 43(6), pp. 693-725.

Brewer, D. (1995a). Cognitive Indicators of Knowledge in Semantic Domains. Journal of Quantitative Anthropology, 5(2), pp. 107-128.

Brewer, D. (1995b). Patterns in the Recall of Persons in a Department of a Formal Organization. Journal of Quantitative Anthropology, 5(4), pp. 255-284.

Brewer, D.D. (2002). Supplementary interviewing techniques to maximize output in free listing tasks. Field Methods, (14), pp. 108-118.

Chipperfield, S.R. (2012). The effect of group diversity on learning on a university-based foundation course. Journal of Further and Higher Education, 36(3), pp. 333-350.

Cho, H., Gay, G., Davidson, B., \& Ingraffea, A. (2007). Social networks, communication styles, and learning performance in a CSCL community. Computers \& Education, 49(2), pp. 309-329.

Coleman, J.S. (1988). Social Capital in the Creation of Human Capital. The American Journal of Sociology, 94(Supplement), pp. S95-S120.

Dawson, S. (2008). A study of the relationship between student social networks and sense of community. Educational Technology \& Society, 11, pp. 224-238.

Decuyper, S., Dochy, F., \& Van den Bossche, P. (2010). Grasping the dynamic complexity of team learning: An integrative model for effective team learning in organisations. Educational Research Review, 5(2), pp. 111-133.

Deeter-Schmelz, D.R., Kennedy, K.N., \& Ramsey, R.P. (2002). Enriching Our Understanding of Student Team Effectiveness. Journal of Marketing Education, 24, pp. 114-124.

Di Vincenzo, F., \& Mascia, D. (2012). Social capital in project-based organizations: Its role, structure, and impact on project performance. International Journal of Project Management, 30(1), pp. 5-14.

Draper, S.W. (2008). Tinto's model of student retention. Departmnent of Psychology, University of Glasgow.

Eggens, L., Werf, M.P.C., \& Bosker, R.J., 2007. The influence of personal networks and social support on study attainment of students in university education. Higher Education, 55(5), pp. 553-573.

Festinger, L. (1950). Informal social communication. Psychological Review, 57, pp. 271-282.

Gorse, C.A., \& Emmitt, S. (2007). Communication behaviour during management and design team meetings: a comparison of group interaction. Construction Management and Economics, 25(11), pp. 1197-1213.

Grabher, G., \& Thiel, J. (2015). Projects, people, professions: Trajectories of learning through a mega-event (the London 2012 case). Geoforum, pp. 1-10.

Gundeson, D.E., \& Moore, J.D. (2008). Group Learning Pedagogy and Group Selection. International Journal of Construction Education and Research, 4, pp. 34-45.

Handford, M., \& Matous, P. (2015). Problem-solving discourse on an international construction site: Patterns and practices. English for Specific Purposes, 38, pp. 85-98. 
Handley, K., Sturdy, A., Fincham, R., \& Clark, T. (2006). Within and Beyond Communities of Practice: Making Sense of Learning Through Participation, Identity and Practice. Journal of Management Sciences, 43(3), pp. 641-653.

Havnes, A. (2008). Peer-mediated learning beyond the curriculum. Studies in Higher Education, 33(2), pp. 193-204.

Haythornthwaite, C. (2002). Building social networks via computer networks: Creating and sustaining distributed learning communities. In K.A. Renninger \& W. Shumar, Building Virtual Communities: Learning and Change in Cyberspace. Cambridge, UK: Cambridge University Press, pp. 159-190.

Hoegl, M., \& Gemuenden, H.G. (2001). Teamwork Quality and the Success of Innovative Projects: A Theoretical Concept and Empirical Evidence. Organization Science, 12(4), pp. 435-449.

Johnson, D.W., \& Johnson, R.T. (2009). An Educational Psychology Success Story: Social Interdependence Theory and Cooperative Learning. Educational Researcher, 38(5), pp. 365-379.

Keung, C.C.W., \& Shen, L.Y. (2013). Measuring the Networking Performance for Contractors in Practicing Construction Management. Journal of Management in Engineering, 29(4), pp. 400-406.

Koh, T.Y., \& Rowlinson, S. (2014). Project team social capital, safety behaviors, and performance: A multi-level conceptual framework. Procedia Engineering, 85, pp. 311318.

Lave, J. (1996). Teaching, as Learning, in Practice. Mind, Culture, and Activity, 3(3), pp. 149_ 164.

Lin, S. (2015). An Analysis for Construction Engineering Networks. Journal of Construction Engineering and Management, 141(5), p.04014096.

Lindkvist, L. (2005). Knowledge communities and knowledge collectivities: a typology of knowledge work in groups. Journal of Management Studies, 42, pp. 1189- 1210.

Lizzio, A., \& Wilson, K. (2010). Self-managed learning groups in higher education: Students' perceptions of process and outcomes. British Journal of Educational Psychology, 75(3), pp. 373-390.

Maghiar, M., Sturges, D., Maurer, T., \& Jackson, M. (2015). Exploration of Student Perceptions, Behaviors and Academic Performance in Construction Management Classes. International Journal of Construction Education and Research, pp. 1-16.

Mann, S.J., (2001). Alternative Perspectives on the Student Experience: alienation and engagement. Studies in Higher Education, 26(1), pp. 7-19.

Martin, A.J., \& Dowson, M. (2009). Interpersonal Relationships, Motivation, Engagement, and Achievement: Yields for Theory, Current Issues, and Educational Practice. Review of Educational Research, 79(1), pp. 327-365.

Muir, I., \& Langford, D. (1994). Managerial behaviour in two small construction organisations. International Journal of Project Management, 12(4), pp. 244-253.

Mutis, I., \& Issa, R.R.A. (2011). Learning to Appropriate a Project Social Network System Technology. In Proceedings, International Workshop on Computing in Civil Engineering, Miami, Florida, 19-22 June, ASCE. pp. 826-833.

Nahapiet, J., \& Ghoshal, S. (1998). Social capital, intellectual capital, and the organizational advantage. Academy of Management Review, 23(2), pp. 242-266. 
Orsmond, P., Merry, S., \& Callaghan, A. (2011). Communities of practice and ways to learning: charting the progress of biology undergraduates. Studies in Higher Education, 38(6), pp.890-906.

Osterman, K.F. (2000). Students' Need for Belonging in the School Community. Review of Educational Research, 70(3), pp. 323-367.

Oztok, M., Zingaro, D., Makos, A. \& Hewitt, J. (2015). Capitalizing on social presence: The relationship between social capital and social presence. Internet and Higher Education, 26, pp. 19-24.

Pauget, B., \& Wald, A. (2013). Relational competence in complex temporary organizations: The case of a French hospital construction project network. International Journal of Project Management, 31(2), pp. 200-211.

Pryke, S. (2012). Social Network Analysis in Construction. Chichester: Wiley-Blackwell.

Quinlan, M. (2004). From the bush: The frontline of health care in a Caribbean village. Belmont, CA: Wadsworth.

Quinlan, M. (2005). Considerations for Collecting Freelists in the Field: Examples from Ethobotany. Field Methods, 17(3), pp.219-234.

Ryan, G.W., Nolan, J.M. \& Yoder, P.S. (2000). Successive Free Listing: Using Multiple Free Lists to Generate Explanatory Models. Field Methods, 12(2), pp. 83-107.

Schrauf, R.W., \& Sanchez, J. (2010). Age Effects and Sample Size in Free Listing. Field Methods, 22(1), pp. 70-87.

Sense, A.J. (2011). The project workplace for organizational learning development. International Journal of Project Management, 29(8), pp. 986-993.

Strauss, P., U, A., \& Young, S. (2011). "I know the type of people I work well with": student anxiety in multicultural group projects. Studies in Higher Education, 36(7), pp. 815-829.

Summers, J.J., \& Svinicki, M.D. (2007). Investigating classroom community in higher education. Learning and Individual Differences, 17(1), pp. 55-67.

Sutrop, U. (2001). List Task and a Cognitive Salience Index. Field Methods, 13(3), pp. 263-276.

Thompson, E., \& Juan, Z. (2006). Comparative cultural salience: Measures using free-list data. Field Methods, 18(4), p.398.

Thomson, D., Kaka, A., Pronk, L. \& Alalouch, C. (2012). The use of freelisting to elicit stakeholder understanding of the benefits sought from healthcare buildings. Construction Management and Economics, 30(4), pp. 309-323.

Toor, S.U.R., \& Ofori, G. (2008). Developing Construction Professionals of the 21st Century: Renewed Vision for Leadership. Journal of Professional Issues in Engineering Education and Practice, 134(3), pp. 279-286.

Van den Bossche, P., \& Segers, M. (2013). Transfer of training: Adding insight through social network analysis. Educational Research Review, 8(C), pp. 37-47.

Villar, E., \& Albertín, P. (2010). "It is who knows you." The positions of university students regarding intentional investment in social capital. Studies in Higher Education, 35(2), pp. 137-154.

Vorakulpipat, C., Rezgui, Y., \& Hopfe, C.J. (2010). Value creating construction virtual teams: A case study in the construction sector. Automation in Construction, 19(2), pp. 142-147.

Wei, J., Zheng, W., \& Zhang, M. (2011). Social capital and knowledge transfer: A multi-level analysis. Human Relations, 64(11), pp. 1401-1423. 
Wilcox, P., Winn, S., \& Fyvie-Gauld, M. (2005). "It was nothing to do with the university, it was just the people": the role of social support in the first-year experience of higher education. Studies in Higher Education, 30(6), pp. 707-722.

Wildemeersch, D., Jansen, T., Vandenabeele, J., \& Jans, M. (1998). Social Learning: a new perspective on learning in participatory systems. Studies in Continuing Education, 20(1), pp. 251-265.

Winkler-Rhoades, N., Medin, D., Waxman, S.R., Woodring, J. \& Ross, N.O. (2010). Naming the Animals that Come to Mind: Effects of Culture and Experience on Category Fluency. Journal of Cognition and Culture, 10(1), pp. 205-220.

Yeatts, D. E., \& Hyten, C. (1998). High performing self managing work teams. Thousand Oaks, CA: Sage. 